\title{
A review of the syndemic components of male same-sex intimate partner violence
}

\author{
Matt L. Pimentel * \\ University of Missouri-Kansas City, Los Osos, United States
}

Received: August 29, 2014

Accepted: October 16, $2014 \quad$ Online Published: October 19, 2014

DOI: $10.5430 /$ jnep.v5n1p19

URL: http://dx.doi.org/10.5430/jnep.v5n1p19

\begin{abstract}
Intimate partner violence is an underreported, stigmatized, and deleterious reality affecting a greater proportion of gay and bisexual men than their heterosexual counterparts. Syndemic theory suggests that many health conditions do not occur in a vacuum, but rather act synergistically, with factors reinforcing each other. Syndemic factors for those who experience male same-sex intimate partner violence (MSSIPV) include depression, sexual compulsivity, substance abuse, childhood sexual abuse (CSA), and HIV infection. This manuscript contains a review of the literature on syndemic factors of MSSIPV that increase negative health outcomes. Acknowledging and understanding the interrelation of these problems is a critical step in developing interventions to address this syndemic in the population of gay men.
\end{abstract}

Key Words: Intimate partner violence, Male same-sex intimate partner violence, Childhood sexual abuse

\section{Introduction}

Intimate partner violence (IPV) affects couples in all population groups. Historically, IPV was considered a heterosexual issue, with males as the perpetrators of violence against heterosexual women who encountered an indifferent police response, a minimizing of abuse by authorities, and a lack of available resources to address the problem. ${ }^{[1,2]}$ While extensive literature was available about heterosexual IPV, until the mid-1980's such violence was invisible in the gay male community. The past thirty years has seen a gradual acknowledgement of the existence of the problem of male same sex intimate partner violence (MSSIPV), or "a pattern of violent and cohesive behaviors whereby a gay man seeks to control the thoughts, beliefs, or conduct of an intimate partner or to punish the intimate for resisting the perpetrator's control". ${ }^{[3]}$ Recognition of MSSIPV is an important step in the development of effective interventions. The goal of this paper is to summarize relevant literature on the interrelated factors associated with MSSIPV.

\section{Methodology}

Using the search terms gay men, same-sex intimate partner violence, and domestic violence, CINAHL, MEDLINE, PubMed, and PschINFO were searched for information on MSSIPV and its link to other syndemic variables. An initial review was done to estimate the amount of potential MSSIPV in the current literature. This was followed by an assessment of associated factors, or syndemic variables, consolidating and matching evidence with health outcomes and discussing possible interventions.

\section{Findings}

\subsection{Estimating MSSIPV}

Challenges exist in accurately estimating victims and perpetrators of MSSIPV because general discrimination against LGBT individuals makes acknowledgement a source of fear and stigma. Such discrimination is still legal in many states, leaving many gay men closeted and able to be outed by

\footnotetext{
* Correspondence: Matt L. Pimentel, RN, MSN, PhD(c); Email: matt_pim2004@yahoo.com; Address: University of Missouri-Kansas City, Los Osos, United States.
} 
a partner, an issue non-existent in heterosexual relationships. ${ }^{[4]}$ Early male physical socialization with rough play and competitive sports easily translates into normalized aggression between two men in a romantic relationship. ${ }^{[5]}$ Gay men also face the barrier of societal homophobia and heteronormativity, that is, society's view of homosexuality as deviant and that everyone who is not heterosexual, is not 'normal'. [6]

In the 21st century, the United States has undergone a change in perspective on homosexuality, with society more accepting of the LGBT community. The landmark Federal Supreme Court case, United States vs. Windsor (2013), which overturned the 1996 federal Defense of Marriage Act and allowed State Supreme Courts to decided marriage qualifications in their own states, the rescinding of the discriminatory military policy of "don't ask, don't tell," and possible passage of the Federal Employment Non-Discrimination Act are all promising signs of progress. ${ }^{[7,8]}$ Gay marriage is on the legislative agenda in many states and is currently legal in 19 States and the District of Columbia, with state Supreme Courts considering anti-gay marriage laws unconstitutional on an almost monthly basis. However, discrimination and social stigma continue to exist for gay men, especially those who are young and/or from racial/ethnic minority populations..$^{[9,10]}$ This stigma, along with bullying of non-gender conforming adolescents and negative media messaging results in high rates of mental health problems among gay men. ${ }^{[11]}$

Over the past twenty years, researchers have identified varying rates of MSSIPV, including psychological abuse rates between $33 \%$ to $73.2 \%,{ }^{[12]}$ sexual violence rates in current relationships from $9.8 \%$ to $28.1 \%,{ }^{[13]}$ and physical abuse rates from $11.8 \%$ to $45.1 \% .{ }^{[14]}$ A methodological weakness of many of the studies of MSSIPV is the widespread use of convenience samples and the lack of studies using random sampling. The use of such samples is often necessary because of the social stigma attached to gay status, leaving many reticent to disclose identity. Hospitals and insurance records often lack relevant identifiers and few databases are available that contain a list of gay males ready to participate in a survey.

The most widely used sample for assessing MSSIPV is that of Greenwood ${ }^{[15]}$ and colleagues which used the Urban Men's Health Study, which recruited from the large urban areas of San Francisco, Los Angeles, Chicago, and New York City. This study used random sampling methodology through random-digit dialing in census tracks with high numbers of gay/bisexual men, or men who have sex with men (MSM). To identify its 2,881 participants, the study applied the definition of abuse available from the standardized and routinely used Conflict Tactics Scale instrument. ${ }^{[16]}$ The results are the most widely referenced indicator of urban MSSIPV and reported that $39.2 \%$ of the sample of MSM had experienced victimization of at least one form of abuse in the last five years. Psychological abuse was experienced by $34 \%$ of the sample, physical abuse by $22 \%$ and sexual by $5.1 \%$.

Some international studies have been conducted on MSSIPV. For example, DiStefano ${ }^{[17]}$ and Mak, Chong ${ }^{[18]}$ reported MSSIPV in Japan and Hong Kong, respectively, albeit with small $(\mathrm{n}<400)$ sample. A study of MSSIPV in six countries including the United States, Canada, United Kingdom, Australia, South Africa, and Brazil reported rates of MSSIPV similar to the United States. ${ }^{[19]}$ Generalizability of these results to U.S. populations is limited because of the different cultural structures in these countries.

\subsection{Factors associated with MSSIPV}

A variety of correlates of MSSIPV have been identified, including childhood sexual abuse, substance abuse, depression, sexual compulsivity and HIV infection.

The association between childhood sexual abuse (CSA) and MSSIPV is strong with reported rates between $11 \%-37 \%$; these rates are higher for African-American MSM, where sexual and physical abuse at an early age correlate highly with not only MSSIPV but also depression, substance abuse, suicide attempts, alcoholism, smoking, sexually transmitted disease, severe obesity, and a myriad of chronic diseases. ${ }^{[14,20]}$ A meta-analysis reported that sexual minority children/adolescents have much higher rates of CSA, parental psychical abuse, assault at school, and fear of assault at school, than non-sexual minority children. ${ }^{[21]}$ A history of CSA was the strongest predictor of victimization; ${ }^{[22]}$ this may be explained by internalization of early sexual abuse that serves as a template of normality for gay men. Along with social stigmatization, gay men may subconsciously have normalized such violation at a younger age, and thus continuation warranted at a later age.

Substance abuse is higher among gay men than heterosexual men and among victims of MSSIPV. Groups of gay men who both abuse drugs and are HIV-infected have the highest rates of MSSIPV. ${ }^{[23]}$ Among gay men who were involved in mutual partner violence or in which both participants were aggressors, self-report of multiple substance abuse are unusually high at 64\% (Kelly, Izienicki, Bimbi, \& Parsons, 2011). Substance abuse rates as high as $50 \%$ have been reported among Hispanic MSM ${ }^{[24]}$ MSSIPV, substance abuse and sexual risk seem to be identified together in foreign born Hispanic MSM, with one study reporting $56 \%$ of rural, immigrant MSM using marijuana and 27.1\% cocaine; high levels of risky sexual behaviors and sex with multiple partners. ${ }^{[25,26]}$ Drug and alcohol use, including the use of methamphetamine, which is particularly popular among gay men lowers sexual and physical inhibitions and alters critical thinking, both of which lead to high risk sexual behavior and aggression. ${ }^{[27,28]}$ Higher rates may also be a function of stigma and discrimination in the homes, workplaces, and 
communities of gay men. ${ }^{[24,29]}$

Depression rates and other mental health problems in the form of affective disorders, anxiety disorders, and prevalence of suicide attempts are higher among gay/bisexual men compared to heterosexual. ${ }^{[30]}$ The large random sample of Urban Men's Health Study reported 17\% of MSM self-reported as depressed, with another $12 \%$ reporting as distressed (a less symptomatic form of depression). ${ }^{[31]}$ Similar to patterns of victimization of heterosexual IPV, gay men in abusive relationships have higher rates of depression and other mental health issues, participate in high-risk sexual behavior, and utilize illegal substances than those who are not in an abusive relationships. ${ }^{[32]}$ Among Hispanic MSM, depression has been reported in approximately $25 \%$ 33\%. ${ }^{[2]}$ The Multicenter AIDS Cohort Study (MACS) study reported high rates of depressive symptoms among gay/bisexual men. ${ }^{[33]}$ This study was the first to institute a life course discussion of exposure to stresses that coincided with later syndemic production variables. A possible pathway exists from childhood and adolescent stressors of bullying, violence, or other gay-specific childhood challenges to mental health challenges and depression in later adulthood. ${ }^{[7]}$

Sexual compulsivity is the constant and increasing attraction for sexual conquests and sexual actions that lead to disruption in a person's emotional and psychological life. ${ }^{[34]}$ MSM who are sexually compulsive have higher rates of unprotected anal intercourse, higher number of different sexual partners, more sex under the influence of drugs, greater rates of sexual transmitted diseases, greater rates of HIV infection, and less disclosure of HIV status than those who are not sexually compulsive. ${ }^{[35-37]}$ Sexual compulsivity is highly correlated with MSSIPV, depression, CSA, and multi-drug use. ${ }^{[34]}$ As sexual compulsivity is also correlated with MSSIPV, partner shaming or passivity by the abused partner is considered "normal" or "acceptable" behavior for those who are or feel that their partners are not worthy of such respect.

HIV-infected individuals have high rates of MSSIPV, ranging from $22.4 \%$ to $85.4 \%$ depending on the sample size methodology, or instruments used to assess for IPV. ${ }^{[23,38]}$ HIV-infection is highly correlated with CSA, MSSIPV, depression, and substance abuse, as well as sexual compulsion and tobacco use. ${ }^{[28,39]}$ The greater the number of these correlations, the higher the rate of HIV-infection. Though not fully explored at all levels, sexual risk taking is synergized by substance usage and tenants of mental health issues such as hostility, depression, and anxiety, which lead to HIV-infection. ${ }^{[40]}$

\subsection{What is a syndemic?}

A syndemic is a collection of related variables that explain negative health outcomes for specific populations of peo-

Published by Sciedu Press ple. The term refers to an amalgamation of epidemics that work synergistically and collectively to make each of epidemics more egregious than if approached alone. ${ }^{[28]}$ The word "syndemic" is a portmanteau, or a word than blends two ideas or concepts together. ${ }^{[39]}$ This neologism begins with synergy, that is, when two or more things work together than just an original premise, and demic, which is a Greek word meaning people or population. ${ }^{[39]}$ A syndemic is a situation where a population is affected by two or more variables that inflict damage more effectively and cumulatively than any single variable.

Singer ${ }^{[41]}$ originally developed the idea of a syndemic in his examination of substance abuse, violence, and HIV/AIDS among Puerto Rican men in Hartford, Connecticut, documenting the collective, increased propensity for each of these factors to reinforce each other and made the rate of each greater than if they had occurred alone. Syndemics have also been suggested for the confluence of risk behaviors reported in certain Hispanic populations and for the problems facing women in the criminal justice system. ${ }^{[42,43]}$ Acknowledging the existence of syndemic allows researchers and clinicians to focus on these specific correlates and to better able to provide interventions and plans of treatment.

\subsection{MSSIPV as a syndemic}

While most research addresses MSSIPV as an isolated problem, the reality is that MSSIPV does not occur in isolation. Gay men appear to have more negative physical and mental health outcomes than the general population which are hypothesized to be the result of the stigma, discrimination, and internalized homophobia of many gay men. ${ }^{[28,44]}$ Specific outcomes include a significant correlation between MSSIPV and depression, ${ }^{[4]}$ sexual compulsivity, ${ }^{[34]}$ childhood sexual abuse, ${ }^{[22,46]}$ substance abuse, ${ }^{[32,47,48]}$ and HIV infection. ${ }^{[34,49-51]}$

The syndemic factors of sexual compulsivity, depression, childhood sexual abuse, intimate partner violence, and polydrug use have all been reported to have strong associations with high-risk sexual behavior and HIV-infection. ${ }^{[34]}$ This has been duplicated in a cross-sectional study in four large cities with high proportion of gay men ${ }^{[52]}$ and with an urban and diverse sample of young men who have sex with men (YMSM). ${ }^{[53]}$ Cigarette smoking, another potential syndemic variable, was highly correlated with heavy alcohol use, depression, and intimate partner violence, as researchers advocated a generalized approach to smoking cessation. ${ }^{[54]}$ Cigarette smoking was also much higher for those HIV-infected and experiencing IPV along with independent association with childhood sexual abuse and prior mental health issues. ${ }^{[23]}$ Through structural equation modeling, mental health issues and substance abuse comes before high-risk sexual behaviors in regard to activity; whereas prior research that used regression and correl- 
ative models subsume simultaneity with which these correlates match. ${ }^{[9,55]}$

\subsection{Minority syndemics}

Higher rates of abuse experienced by sexual minority youth may be the driving force behind mental health problems, substance abuse, high risk sexual behavior and HIVinfection; this population is more likely to experience sexual abuse, parental physical abuse and assault at school compared to sexual nonminority individuals. ${ }^{[21]}$ Additionally, youth that hit earlier milestones of disclosing sexual orientation and first awareness of same-sex attraction have much higher rates of adulthood harassment, depression, intimate partner violence, and HIV-infection. ${ }^{[56]}$ Klein ${ }^{[57]}$ used syndemic production and structural equation modeling to demonstrate that condom usage for gay men was largely determined by childhood maltreatment, psychological functioning, and attitudes toward personal safety to whether compliance with condom usage was consistent.

Bisexual and gay male Hispanic men have higher rates of perpetration and victimization of MSSIPV along with other syndemic challenges such as depression and drug abuse. ${ }^{[58]}$ Another study that focused exclusively on gay and bisexual Hispanic men, identified lifetime IPV at $52 \% ;{ }^{[59]}$ HIVinfected men with higher rates of IPV also had higher rates of high risk sexual behaviors. ${ }^{[12]}$ These same Hispanic gay men have much higher rates of unprotected anal intercourse and binge drinking.

African-American gay men also identified high rates of syndemic variables with many relationships between such variables; most notably that substance abuse was a clear indicator for MSSIPV ${ }^{[7]}$ Interestingly, gay neighborhoods were protective of substance abuse for men of color. ${ }^{[27]}$ Structural equation modeling suggest that HIV prevention programs and HIV care must be congruent and simultaneous with drug abuse messaging and mental health therapies. ${ }^{[55]}$

Canadian researchers identified those that experience IPV and are HIV-infected have lower engagement with medication adherence and progress faster to AIDS diagnosis with increased hospitalization, than those who do not experience IPV, especially for non-Caucasians. ${ }^{[23]}$ Men of color who have unprotected anal intercourse with other men also tended to have sex with those of unknown or serodiscordant HIV status, be under the influences of drugs, and seek sex on the internet. ${ }^{[60]}$

Stress over one's self-identity as a sexual minority may be the basis for this syndemic and the confluence of behaviors. Meyer ${ }^{[44]}$ proposed a theoretical framework of minority stress, which was based on the constructs of sex, race, and sexual orientation and suggested that the conventional culture ascribes "defectiveness" to those that do not mirror the majority. Minority individuals may, in turn, incorporate and internalize societal messages, whether overt or slight, into their psyches. ${ }^{[61]}$ The repeated, unmediated occurrences of these stressors lead to maladaptive responses by the individual and negative mental health conditions. Minority stress theory suggests that MSSIPV is a maladaptive behavior resulting from being a sexual minority member. Meyer ${ }^{[44]}$ focused exclusively on gay men and posited that the maladaptive behaviors were due to internalized homophobia, a perceived stigma of being a sexual minority member, and discrimination, the actual external harm. It is not a coincidence that this perceived stigma has segued into an HIV-stigma that also shares the same syndemic components of mental health disparities and high-risk sexual behaviors. Depression and traumatic lifetime events have a strong correlated relationship with HIV infection, which is partially mediated by high-risk sexual behaviors. ${ }^{[62]}$

On the protective side, family acceptance during the "coming out" process for gay teenagers may counter depression, suicidality, and substance abuse. ${ }^{[63]}$ This family acceptance predicts better overall social supports, promotes greater selfesteem, and more positive health status than those who do not have such acceptance. In a study of young gay men, frequent drug use, large party scenes, hostility, depression, and anxiety, along with substance abuse, synergistically, led to sexual risk taking. ${ }^{[40]}$

\section{Discussion}

Identifying MSSIPV as a syndemic allows researchers and practitioners to develop interventions that address its interrelated components. Unfortunately, specific strategies to address these interrelated issues are not readily apparent. Focusing on just MSSIPV will not be successful with individuals who have depression, a past history of CSA, and drug use. Treatment and/or therapy must be included not just MSSIPV, but also drug addiction, sexual compulsivity, and depression. For those who are at high-risk for HIV-infection, programs must also include content that concurrently acknowledges substance abuse and other mental health issues. ${ }^{[64]}$ As an example, some researchers have discussed higher rates of substance abuse, mental health issues and HIV-infection of gay men, while resilience and social supports may provide a mediating role with this population. ${ }^{[1]}$ Childhood sexual abuse, bullying of adolescence peers, and the early onset of smoking, not only raises the rate of potential MSSIPV, but can be thwarted with welltimed and positive influences by parents and school administration. ${ }^{[65]}$

Health care and social service providers must be cognizant of the signs and symptoms of MSSIPV. Gay men presenting with one of the syndemic variables are highly likely to others.

Being competent in LGBT healthcare and most importantly, healthcare regarding MSM, especially if the provider is heterosexual, is paramount for effective communication be- 
tween patient and practitioner. ${ }^{[66]}$ Counseling should be cognitively based and focus on holistic remedies incorporating all the syndemic variables instead of just focusing on MSSIPV ${ }^{[67]}$ Researchers are encouraged to test interventions with victims and perpetrators of MSSIPV, especially focusing on gay and bisexual men of color and those that are HIV-infected, as they are often neglected in, the extant research and those individuals have shown to have the greatest need.

Syndemics should be handled in a multi-disciplinary man-

\section{References}

[1] Walker LE. The battered woman. New York, BY: Harper \& Row, Publishers, Inc.; 1979

[2] Letellier P. Gay and bisexual male domestic violence victimization: Challenges to feminist theory and responses to violence. Violence Vict. 1994; 9(2): 95-106. PMID:7696200

[3] Hart B. Lesbian Battering: A examination. In: Lobel K, editor. Naming the Violence. Seattle: Seal Press; 1986.

[4] Finneran C, Stephenson R. Intimate partner violence among men who have sex with men: A systematic review. Trauma, Violence, \& Abuse. 2013; 14(2): 168-85. PMID:23271429 http://dx.doi.o $\mathrm{rg} / 10.1177 / 1524838012470034$

[5] Messinger AM. Invisible victims: Same-sex IPV in the national violence against women survey. Journal of interpersonal violence. 2011; 26(11): 2228-43. PMID:20829231 http://dx.doi.org/1 $0.1177 / 0886260510383023$

[6] Craft SM, Serovich JM, McKenry PC, Lim J. Stress, attachment style, and partner violence among same-sex couples. Journal of GLBT Family Studies. 2008; 4(1): 57-73. http://dx.doi.org $/ 10.1080 / 15504280802084456$

[7] Dyer TP, Shoptaw S, Guadamuz TE, Plankey M, Kao U, Ostrow D, et al. Application of syndemic theory to black men who have sex with men in the multicenter AIDS cohort study. Journal of Urban Health. 2012; 89(4): 697-708. PMID:22383094 http://dx.doi . org/10.1007/s11524-012-9674-x

[8] Herrick AL, Stall R, Chmiel JS, Guadamuz TE, Penniman T, Shoptaw S, et al. It gets better: Resolution of internalized homophobia over time and associations with positive health outcomes among MSM. AIDS \& Behavior. 2013; 17(4): 1423-30. PMID:23283578 http://dx.doi.org/10.1007/s10461-012-0392-x

[9] Halkitis PN, Moeller RW, Siconolfi DE, Storholm ED, Solomon TM, Bub KL. Measurement model exploring a syndemic in emerging adult gay and bisexual men. AIDS and behavior. 2013; 17(2): 662-73. PMID:22843250 http://dx.doi.org/10.1007/s1046 1-012-0273-3

[10] Shilo G, Savaya R. Mental health of lesbian, gay, and bisexual youth and young adults: Differential effects of age, gender, religiosity, and sexual orientation. Journal of Research on Adolescence. 2012; 22(2): 310-25. http://dx.doi.org/10.1111/j.1532-7 795.2011.00772.x

[11] Herrick AL, Lim SH, Wei C, Smith H, Guadamuz T, Friedman MS, et al. Resilience as an untapped resource in behavioral intervention design for gay men. AIDS and behavior. 2011; 15(Suppl 1): S25-S9. PMID:21344306 http://dx.doi.org/10.1007/s1046 1-011-9895-0

[12] Nieves-Rosa LE, Carballo-Dieguez A, Dolezal C. Domestic abuse and HIV-risk behavior in Latin America men who have sex with men in New York City. Journal of gay \& lesbian social services. 2000; (11): 77-90. http://dx.doi.org/10.1300/J041v11n01_04 ner, and not pigeon-holed into diagnostic medical model categories. $^{[39]}$ Clinicians must incorporate all the issues with which a gay male patient presents for proper treatment and coalesce other syndemic variables into an evidencebased and social coherent treatment plan that is straightforward and free from stigmatizing discussion of the patient's orientations or life choices. While clinicians may be reticent to open the proverbial Pandora's Box of MSSIPV, depression, drug abuse and past CSA, effective cultural competence demands such an approach with this vulnerable population.
[13] Pantalone DW, Schneider K, Valentine S, Simoni JM. Investigating partner abuse among HIV-positive men who have sex with men. AIDS \& Behavior. 2012; 16(4): 1031-43. PMID:21822954 http://dx.doi.org/10.1007/s10461-011-0011-2

[14] Welles SL, Corbin TJ, Rich JA, Reed E, Raj A. Intimate partner violence among men having sex with men, women, or both: Earlylife sexual and physical abuse as antecedents. J Community Health. 2011; 36(3): 477-85. PMID:21116698 http://dx.doi.org/10. 1007/s10900-010-9331-9

[15] Greenwood GL, Relf, M. V., Huang, B., et al. Battering victimization among a probability-based sample of men who have sex with men. Am J Public Health. 2002; 92(12): 1964-9. http://dx.doi . org/10.2105/AJPH. 92.12.1964

[16] Straus MA, Hamby SL, Boney-McCoy S, Sugarman DB. The revised conflict tactics scales (CTS2): Development and preliminary psychometric data. Journal of Family Issues. 1996; 17(3): 283-316. http://dx.doi.org/10.1177/019251396017003001

[17] DiStefano AS. Intimate partner violence among sexual minorities in Japan: Exploring perceptions and experiences. Journal of homosexuality. 2009; 56(2): 121-46. PMID:19197646 http://dx.doi.o $\mathrm{rg} / 10.1080 / 00918360802623123$

[18] Mak WWS, Chong ESK, Kwong MMF. Prevalence of same-sex intimate partner violence in Hong Kong. Public health. 2010; 124(3): 149-52. PMID:20202655 http://dx.doi.org/10.1016/j.puh e. 2010.02 .002

[19] Finneran C, Chard A, Sineath C, Sullivan P, Stepheneon R. Intimate partner violence and social pressure among gay men in six countries. Western Journal of Emergency Medicine. 2012; 13(3): 26071. PMID:22900124 http://dx.doi .org/10.5811/westjem.2 012.3 .11779

[20] Felitti VJ, Anda RF, Nordenberg D, Williamson DF, Spitz AM, Edwards V, et al. Relationship of childhood abuse and household dysfunction to many of the leading causes of death in adults. The adverse childhood experiences (ACE) Study. Am J Prev Med. 1998; 14(4): 245-58. http://dx.doi.org/10.1016/S0749-3797 (98 ) 00017-8

[21] Friedman MS, Marshal MP, Guadamuz TE, Wei C, Wong CF, Saewyc E, et al. A meta-analysis of disparities in childhood sexual abuse, parental physical abuse, and peer victimization among sexual minority and sexual nonminority individuals. Am J Public Health. 2011; 101(8): 1481-94. PMID:21680921 http://dx.doi.org/1 0.2105/AJPH. 2009. 190009

[22] Han SC, Gallagher MW, Franz MR, Chen MS, Cabral FM, Marx BP. Childhood sexual abuse, alcohol use, and PTSD symptoms as predictors of adult sexual assault among lesbians and gay men. Journal Interpersonal Violence. 2013. PMID:23486851 http://dx. doi.o $\mathrm{rg} / 10.1177 / 0886260513479030$

[23] Siemieniuk R, Miller P, Woodman K, Ko K, Krentz H, Gill M. Prevalence, clinical associations, and impact of intimate partner vi- 
olence among HIV-infected gay and bisexual men: A populationbased study. HIV Med. 2012. PMID:23171169

[24] De Santis JP. Factors influencing HIV risk among Hispanic men who have sex with men. Hispanic Health Care International. 2010; 8(3): 122-4. http://dx.doi.org/10.1891/1540-4153.8.3.122

[25] De Santis JP, Gonzalez-Guarda R, Provencio-Vasquez E, Deleon DA. The tangled branches (las ramas enredadas): Sexual risk, substance abuse, and intimate partner violence among Hispanic men Who have sex with men. Journal of transcultural nursing. official journal of the Transcultural Nursing Society / Transcultural Nursing Society. 2013.

[26] Rhodes SD, McCoy TP, Hergenrather KC, Vissman AT, Wolfson $\mathrm{M}$, Alonzo J, et al. Prevalence estimates of health risk behaviors of immigrant Latino men who have sex with men. Journal of Rural Health. 2012; 28(1): 73-83. PMID:22236317 http://dx.doi.o $\mathrm{rg} / 10.1111 / \mathrm{j} .1748-0361.2011 .00373 . \mathrm{x}$

[27] Buttram ME, Kurtz SP. Risk and protective factors associated with gay neighborhood residence. American journal of men's health. 2013; 7(2): 110-8. PMID:22948299 http://dx.doi.org/10.11 $77 / 1557988312458793$

[28] Stall R, Friedman M, Catania JA. Interacting epidemics and gay men's health: A theory of syndemic production among urban gay men. In: Wolitski RJ, Stall R, Valdiserri RO, editors. Unequal opportunity: Health disparities affecting gay and bisexual men in the United States. New York, NY: Oxford University Press; 2008. 25174.

[29] Storholm ED, Halkitis PN, Kupprat SA, Hampton MC, Palamar JJ, Brennan-Ing M, et al. HIV-related stigma as a mediator of the relation between multiple-minority status and mental health burden in an aging HIV-positive population. Journal of HIV/AIDS \& Social Services. 2013; 12(1): 9-25. http://dx.doi.org/10.1080/153 81501.2013 .767557

[30] Cochran SD, Mays VM. Prevalence of primary mental health morbidity and suicide symptoms among gay and bisexual men. In: Wolitski RJ, Stall R, Valdiserri RO, editors. Unequal opportunity: Health disparities affecting gay and bisexual men in the United States. New York, NY: Oxford University Press; 2008; 97-120.

[31] Mills TC, Paul J, Stall R, Pollack L, Canchola J, Chang YJ, et al. Distress and depression in men who have sex with men: The urban men's health study. American Journal of Psychiatry. 2004; 161(2): 278-85. http://dx.doi.org/10.1176/appi.ajp.161.2.278

[32] Houston E, McKirnan DJ. Intimate partner abuse among gay and bisexual men: Risk correlates and health outcomes. Journal of Urban Health. 2007; 84(5): 681-90. PMID:17610158 http://dx.doi.o $\mathrm{rg} / 10.1007 / \mathrm{s} 11524-007-9188-0$

[33] Herrick AL, Lim SH, Plankey MW, Chmiel JS, Guadamuz TT, Kao $\mathrm{U}$, et al. Adversity and syndemic production among men participating in the multicenter AIDS cohort study: A life-course approach. Am J Public Health. 2012; 103(1): 79-85. PMID:23153154 http://dx.doi.org/10.2105/AJPH.2012.300810

[34] Parsons JT, Grov C, Golub SA. Sexual compulsivity, co-occurring psychosocial health problems, and HIV risk among gay and bisexual men: Further evidence of a syndemic. Am J Public Health. 2012; 102(1): 156-62. PMID:22095358 http://dx.doi.org/10.2105 /AJPH. 2011.300284

[35] Kalichman SC, Rompa D. The sexual compulsivity scale: Further development and use with HIV positive persons. Journal of personality assessment. 2001; 76: 379-95. PMID:11499453 http: //dx.doi.org/10.1207/S15327752JPA7603_02

[36] Coleman E, Horvath KJ, Miner M. Compulsive sexual behavior and risk for unsafe sex among Internet using men who have sex with men. Archives Of Sexual Behaviors. 2010; 39(5): 1045 53. PMID:19588239 http://dx.doi.org/10.1007/s10508-0 09-9507-5

[37] Dilley JW, Loeb L, Marson K. Sexual compulsiveness and change in unprotected anal intercourse: Unexpected results from a randomized controlled HIV counseling intervention study. JAIDS. 2008; 48(1): 113-4. PMID:18438179 http://dx.doi.org/10.1097/Q AI. Ob013e3181642293
[38] Ramachandran S, Yonas MA, Silvestre AJ, Burke JG. Intimate partner violence among HIV-positive persons in an urban clinic. AIDS Care. 2010; 22(12): 1536-43. PMID:20924830 http://dx.doi.o $\mathrm{rg} / 10.1080 / 09540121.2010 .482199$

[39] Singer M. Introduction to syndemics: A critical systems approach to public and community health. San Francisco, CA: Jossey-Bass; 2009.

[40] Moeller RW, Halkitis PN, Surrence K. The interplay of syndemic production and serosorting in drug-using gay and bisexual men. Journal of gay \& lesbian social services. 2011; 23(1): 89-106. http://dx.doi.org/10.1080/10538720.2010.538007

[41] Singer M. A dose of drugs, a touch of violence, a case of AIDS: Conceptualizing the SAVA syndemic. Free Inquiry in Creative Sociology. 1996; 24(2): 99-110.

[42] González-Guarda RM, Florom-Smith AL, Thomas T. A syndemic model of substance abuse, intimate partner violence, HIV infection, and mental health among hispanics. Public Health Nurs. 2011; 28(4): 366-78. PMID:21736615 http://dx.doi.org/10.1111 $/ j .1525-1446.2010 .00928 . x$

[43] Kelly PJ, Cheng AL, Spencer-Carver E, Ramaswamy M. A syndemic model of women incarcerated in community jails. Public Health Nurs. 2014; 31(2): 118-25. PMID:24588130 http://dx.d oi .org/10.1111/phn.12056

[44] Meyer IH. Minority stress and mental health in gay men. J Health Soc Behav. 1995; 36(1): 38-56. http://dx. doi.org/10.2307/2 137286

[45] Randle AA, Graham CA. A review of the evidence on the effects of intimate partner violence on men 2012. Available from: http://ww w. apa.org/pubs/journals/releases/men-12-2-97.pdf.

[46] Balsam KF, Rothblum ED, Beauchaine TP. Victimization over the life span: A comparison of lesbian, gay, bisexual, and heterosexual siblings. Journal of Consulting \& Clinical Psychology. 2005; 73(3): 477-87. PMID:15982145 http://dx.doi.org/10.1037 10022-006X.73.3.477

[47] Andersen JP, Blosnich J. Disparities in adverse childhood experiences among sexual minority and heterosexual adults: Results from a multi-state probability-based sample. PLoS One. 2013; 8(1): e54691. PMID:23372755 http://dx.doi.org/10.1371/journ al. pone. 0054691

[48] Chong ESK, Mak WWS, Kwong MMF. Risk and protective factors of same-sex intimate partner violence in Hong Kong. Journal of interpersonal violence. 2013; 28(7): 1476-97. PMID:23295381 http://dx.doi.org/10.1177/0886260512468229

[49] Valentine SE, Bankoff SM, Pantalone DW. Finding meaning after same-sex partner abuse: A content analysis of experiences of men with HIV. Violence and Victims. 2013; 28(1): 161-77. http: //dx.doi.org/10.1891/0886-6708.28.1.161

[50] Siemieniuk R, Miller P, Woodman K, Ko K, Krentz H, Gill M. Prevalence, clinical associations, and impact of intimate partner violence among HIV-infected gay and bisexual men: A populationbased study. HIV Med. 2013; 14(5): 293-302. PMID:23171169 http://dx.doi.org/10.1111/hiv.12005

[51] Heintz AJ, Melendez RM. Intimate partner violence and HIV/STD risk among lesbian, gay, bisexual, and transgender individuals. Journal of interpersonal violence. 2006; 21(2): 193-208. PMID:16368761 http://dx.doi.org/10.1177/08862605052 82104

[52] Stall R, Mills TC, Williamson J, Hart T, Greenwood G, Paul J, et al. Association of co-occurring psychosocial health problems and increased vulnerability to HIV/AIDS among urban men who have sex with men. Am J Public Health. 2003; 93(6): 939-42. http: //dx.doi.org/10.2105/AJPH.93.6.939

[53] Mustanski B, Garofalo R, Herrick A, Donenberg G. Psychosocial health problems increase risk for HIV among urban young men who have sex with men: Preliminary evidence of a syndemic in need of attention. Annals of Behavioral Medicine. 2007; 34(1): 37-45. http://dx.doi.org/10.1007/BF02879919

[54] Yu F, Nehl EJ, Zheng T, He N, Berg CJ, Lemieux AF, et al. A syndemic including cigarette smoking and sexual risk behaviors among 
a sample of MSM in Shanghai, China. Drug \& Alcohol Dependency. 2013.

[55] Halkitis PN, Wolitski RJ, Millett GA. A holistic approach to addressing HIV infection disparities in gay, bisexual, and other men who have sex with men. American Psychologist. 2013; 68(4): 26173. PMID:23688093 http://dx. doi .org/10.1037/a0032746

[56] Friedman MS, Marshal MP, Stall R, Cheong J, Wright ER. Gay-related development, early abuse and adult health outcomes among gay males. AIDS and behavior. 2008; 12(6): 891902. PMID:17990094 http://dx.doi.org/10.1007/s10461-0 07-9319-3

[57] Klein H. Using a syndemics theory approach to study HIV risk taking in a population of men who use the internet to find partners for unprotected sex. Am j. 2011; 5(6): 466-76.

[58] Gonzalez-Guarda RM, De Santis JP, Vasquez EP. Sexual orientation and demographic, cultural, and psychological factors associated with the perpetration and victimization of intimate partner violence among Hispanic men. Issues Ment Health Nurs. 2013; 34(2): $103-$ 9. PMID:23369121 http://dx.doi.org/10.3109/01612840. 2012.728280

[59] Feldman MB, Diaz RM, Ream GL, El-Bassel N. Intimate partner violence and HIV sexual risk behavior among Latino gay and bisexual men. J LGBT Health Res. 2007; 3(2): 9-19. PMID:19835037 http://dx.doi.org/10.1300/J463v03n02_02

[60] Mayer KH, Ducharme R, Zaller ND, Chan PA, Case P, Abbot $\mathrm{D}$, et al. Unprotected sex, underestimated risk, undiagnosed HIV and sexually transmitted diseases among men who have sex with men accessing testing services in a New England bathhouse. Jour- nal of Acquired Immune Deficiency Syndromes. 2012; 59(2): 1948. PMID:22027871 http://dx.doi.org/10.1097/QAI.0b013 e31823bbecf

[61] Brooks VR. Minority stress and lesbian women. Lexington, MA: D.C. Health and Company; 1981. 219.

[62] Jie W, Ciyong L, Xueqing D, Hui W, Lingyao H. A syndemic of psychosocial problems places the MSM population at greater risk of HIV infection. PLoS One. 2012; 7(3): e32312. PMID:22479319 http://dx.doi.org/10.1371/journal .pone.0032312

[63] Ryan C, Russell ST, Huebner D, Diaz R, Sanchez J. Family acceptance in adolescence and the health of LGBT young adults. J Child Adolesc Psychiatr Nurs. 2010; 23(4): 205-13. PMID:21073595 http://dx.doi.org/10.1111/j.1744-6171.2010.00246.x

[64] Safren SA, Reisner SL, Herrick A, Mimiaga MJ, Stall RD. Mental health and HIV risk in men who have sex with men. Journal of Acquired Immune Deficiency Syndromes. 2010; 55 Suppl 2:S747. PMID:21406991 http://dx.doi.org/10.1097/QAI.0b013 e3181fbc939

[65] Russell ST, Ryan C, Toomey RB, Diaz RM, Sanchez J. Lesbian, gay, bisexual, and transgender adolescent school victimization: Implications for young adult health and adjustment. Journal of School Health. 2011; 81(5): 223-30. PMID:21517860 21517860

[66] Ball MJ. Gay men, intimate partner violence, and help-seeking: The incomprehensibility of being a victim 2011 .

[67] Potter SJ, Fountain K, Stapleton JG. Addressing sexual and relationship violence in the LGBT community using a bystander framework. Harv Rev Psychiatry. 2012; 20(4):201-8. PMID:22894729 http://dx.doi.org/10.3109/10673229.2012.712838 